\title{
BMJ Open What affects response rates in primary healthcare-based programmes? An analysis of individual and unit-related factors associated with increased odds of non-response based on HCV screening in the general population in Poland
}

Natalia Parda, ${ }^{1}$ Małgorzata Stepien, ${ }^{1}$ Karolina Zakrzewska, ${ }^{2,3}$ Kazimierz Madaliński, ${ }^{2}$ Agnieszka Kołakowska, ${ }^{2}$ Paulina Godzik, ${ }^{2}$ Magdalena Rosińska ${ }^{1}$

To cite: Parda N, Stẹpień M, Zakrzewska $\mathrm{K}$, et al. What affects response rates in primary healthcare-based programmes? An analysis of individual and unit-related factors associated with increased odds of nonresponse based on HCV screening in the general population in Poland. BMJ Open 2016;6:e013359. doi:10.1136/bmjopen-2016013359

- Prepublication history for this paper is available online. To view these files please visit the journal online (http://dx.doi.org/10.1136/ bmjopen-2016-013359).

Received 6 July 2016 Revised 7 October 2016 Accepted 13 October 2016

CrossMark

For numbered affiliations see end of article.

Correspondence to

Natalia Parda;

nparda@pzh.gov.pl

\section{ABSTRACT}

Objectives: Response rate in public health programmes may be a limiting factor. It is important to first consider their delivery and acceptability for the target. This study aimed at determining individual and unit-related factors associated with increased odds of non-response based on hepatitis $C$ virus screening in primary healthcare.

Design: Primary healthcare units (PHCUs) were extracted from the Register of Health Care Centres. Each of the PHCUs was to enrol adult patients selected on a random basis. Data on the recruitment of PHCUs and patients were analysed. Multilevel modelling was applied to investigate individual and unit-related factors associated with non-response. Multilevel logistic model was developed with fixed effects and only a random intercept for the unit. Preliminary analysis included a random effect for unit and each of the individual or PHCU covariates separately. For each of the PHCU covariates, we applied a two-level model with individual covariates, unit random effect and a single fixed effect of this unit covariate.

Setting: This study was conducted in primary care units in selected provinces in Poland.

Participants: A total of 242 PHCUs and 24480 adults were invited. Of them, 44 PHCUs and 20939 patients agreed to participate. Both PHCUs and patients were randomly selected.

Results: Data on 44 PHCUs and 24480 patients were analysed. PHCU-level factors and recruitment strategies were important predictors of non-response. Unit random effect was significant in all models. Larger and private units reported higher non-response rates, while for those with a history of running public health programmes the odds of non-response was lower. Proactive recruitment, more working hours devoted to the project and patient resulted in higher acceptance of

\section{Strengths and limitations of this study}

n This is the first in-depth study of the experiences of primary care units concerning the delivery and acceptability of public health programmes in Poland.

- This study was carried out on a large and representative sample of primary care units and patients.

- Participating primary healthcare units (PHCUs) could differ from non-participating PHCUs which could have an effect on high response rates observed in study population.

- Methods of sampling of patients employed by PHCUs were not universal which could have resulted in differences in response rates observed.

- Owing to a small number of PHCUs, we were not able to study the independent effects of all unit-level factors.

the project. Higher number of personnel had no such effect.

Conclusions: Prior to the implementation of public health programme, several factors that could hinder its execution should be addressed.

\section{BACKGROUND}

Screening is a widely adopted instrument in the secondary prevention of asymptomatic chronic diseases. In general, it offers an optimal way to ensure earlier, more effective treatment and, consequently, avoid late 
complications of disease. ${ }^{1-3}$ Nevertheless, screening programmes should be designed in a way to avoid overdiagnosis and overtreatment. ${ }^{4}$ Several infectious diseases, for example, viral hepatitis, HIV, chlamydia infections are also candidates for screening programmes. Additional advantage of early detection consists in preventing an onward transmission and reinfections. ${ }^{5-7}$ Effectiveness of screening depends, inter alia, on its acceptability for the target population. It is important to first investigate healthcare system capacity and public acceptance of the programme. $^{89}$

Even well-organised programmes may fail to succeed due to, for example, low coverage rates with an example being the population-based cervical cancer (CC) screening in Poland. It was introduced in 2007; however, CG incidence (15.3) and mortality (7.4) rates in 2012 still exceeded the average rate for the European Union countries $(11.3 ; 3.7) .{ }^{10}$ Low coverage rate may result from ineffective invitation. ${ }^{11} 12$

Introduction of screening programmes into primary healthcare (PHC) may be a solution. There is evidence confirming the effectiveness of these settings in reaching the target population. ${ }^{13-17}$ Involvement of PHC allows for reaching those most at risk who tend to have poorer access to healthcare. ${ }^{18}$ Generally, healthcare system based on PHC is more efficient in tackling health inequalities. ${ }^{19-21}$

Poland adopted healthcare system model based on primary care in 1994. Since then, the role of general practitioners is promoted. ${ }^{22}$ High potential of PHC, however, still seems to be underestimated. The role of PHC is poorly described in policy documents. ${ }^{23}$ Notably, the role of PHC concerning public health interventions is rather limited with only a few preventive programmes conducted. ${ }^{24}$ On the other hand, there is a high accessibility of primary care services. More than $70 \%$ of population take advantage of them. ${ }^{25}$ Greater engagement of PHC in public health programmes could enhance their coverage.

This study aimed at determining individual and unit-based factors associated with increased odds of nonresponse in hepatitis $\mathrm{C}$ virus (HCV) screening in primary health care units (PHCUs). HCV testing was offered to randomly selected individuals registered to participating units. Understanding of factors driving nonresponse rates in $\mathrm{HCV}$ screening programme in $\mathrm{PHC}$ would enhance hepatitis $\mathrm{C}$ prevention. It would also allow anticipating barriers in future public health programmes and propose models improving their coverage.

\section{METHODS}

\section{Study design}

This study is a part of ongoing project 'Improvement of $\mathrm{HCV}$ diagnostics, estimation of $\mathrm{HCV}$ prevalence in general population and analysis of factors associated with HCV prevalence' within the 'Prevention of HCV Infections' programme which was approved by the
Ethics Committee at the National Institute of Public Health-National Institute of Hygiene (NIPH-NIH; Warsaw, Poland). Our study is a post hoc analysis of data collected for the purpose of evaluation of the project. Individual variables were determined before the study started.

\section{Recruitment procedure}

\section{PHCUs}

Sampling frame consisted of all PHCUs located in 10 (out of 16) Polish provinces (dolnoślaskie, kujawskopomorskie, lubelskie, łódzkie, małopolskie, mazowieckie, podkarpackie, podlaskie, pomorskie, zachodniopomorskie). All eligible units were extracted from the Register of Health Care Centres. Sampling was performed, using the mathematical function 'RAND' in Excel. Each PHCU was attributed a random value $(0 \leq \mathrm{V}<1.0)$. Then, data were sorted from the lowest to the highest numbers. First 12 PHCUs on the list were contacted. PHCUs were informed that they would be rewarded for each patient recruited $(€ 13$ per patient and additional $€ 26$ for $\mathrm{HCV}$-infected patient; EUR*=PLN4.26). Payment was transferred to the PHCU's account. PHCUs were encouraged to use these resources to ensure the most efficient implementation of the programme. They were not, however, requested to provide information how and if these funds were distributed to personnel. Other units were invited if there was refusal or non-response to invitation.

\section{Patients}

Each PHCU selected adults from their list of patients. Exclusion criteria were: age $<18$ years and diagnosis of hepatitis $\mathrm{C}$ provided patient was under infectious disease specialist control. Systematic sampling was performed by PHCUs to obtain the list of potential participants. Each PHCU had to declare the number of potential participants (200-800 persons; 400 on average) based on the capabilities of PHCUs and the total population served. The proportion of selected individuals out of the total population differed substantially between the PHCUs (from $1 \%$ to $58 \%$ ). In the majority of cases, it accounted for $<10 \%(55 \%)$ of the total population served. PHCUs were instructed on possible methods of patient sampling; however, they were not induced to employ one standard as organisation of patients registries varied widely between PHCUs, ranging from electronic to paper-based, specific to primary care unit or a part of general list in case of multispecialty facilities (different sorting strategies). Therefore, specific method of patient sampling had to be adapted to local registries. The majority of PHCUs $(66 \%)$ relied on Nth name selection technique, that is, every Nth patient (eg, every 5th or every 10th, the $\mathrm{N}$ depended on the size of the population served and the number of declared patients) on the list was selected to be contacted. The modifications of this procedure included stratification of sampling (by the regularity of visits to focus telephone recruitment on 
those who do not visit PHCUs regularly or by the demographic feature, eg, year of birth). Some units were able to apply random sampling. Recruitment of volunteers was not allowed.

Selected patients were contacted using telephone, letter, short message service or face-to-face contact. At least three attempts were recommended for telephonebased contact at different hours. Face-to-face contact was attempted if a patient visited a PHCU due to other reasons or if the study nurse was attending another patient living in the vicinity of that patient (small communities).

During the first contact, a patient was informed on the study and invited to participate. At this stage, patient's eligibility was verified. If a patient met the inclusion criteria, the date of first visit was arranged. Contrary to PHCUs, patients were not paid or rewarded in any other manner for their participation in the study. During such visit, patients were first to provide informed written consent. Then, they were assigned an anonymous identification number, provided a leaflet and counselled on HCV infection. Patients were also to fill in questionnaire on exposures to HCV in non-medical and medical settings. Then, a blood sample was collected for HCV testing. Samples were processed using enzyme immunoassay (EIA). PCR was carried out for reactive samples. Patients were informed when they could receive their test result. HCV-infected individuals attended follow-up visit. Serum samples were processed in the Department of Virology of the NIPH-NIH.

\section{Data collection}

Data on PHCUs were derived from the Register of Health Care Centres and collected during on-site monitoring visits. Such visits were conducted by the coordinators to gather information on the programme's acceptability, challenges, etc. These visits were planned in PHCUs that had already recruited $50 \%$ of patients or less in case of identified difficulties. PHCU personnel were requested to describe their recruitment process and experience in running public health programmes.

The database of invitations from 44 randomly selected PHCUs was analysed. Information on invitation results were documented, using a special data format. Provided a patient refused to participate in the project during the first or next contacts, the recorder was to note the basic information (age, gender, place of residence, date of contact and reason of refusal). Other information such as socioeconomic factors (eg, education, income) was not included in the database used for this analysis. These data were gathered only for patients who agreed to participate in the study. Each PHCU was asked to send an anonymised list of individuals invited on a weekly basis.

\section{Definition of the variables}

Mode of invitation was determined on the basis of interviews with personnel. We defined passive modes of invitation as traditional mail or short message service, active as telephone invitation or in person invitation when a person attended the unit for some other reason and very active as using personal contacts and community nurses to recruit patients directly from households. Since only one PHCU relied solely on passive invitation modes and the majority of units used mixed strategies, we classified unit invitation modes into the following categories: passive-active (using passive modes in parallel to active modes or using passive modes at the beginning), active and active-very active (using active modes in parallel to very active).

Information on the project was disseminated through its website and media. Furthermore, PHCUs were provided with information leaflets. They could also propagate the project locally, using their own website, through local events, etc. If any of these additional activities were undertaken, the PHCU was classified as having local promotion programme.

The total working time devoted to a patient was not measured directly. To estimate the time spent per patient, we used the recruitment monitoring data (number of patients invited and number of weeks of effective recruitment). Weeks in which the recruitment was suspended (eg, due to holidays) were excluded from final calculations. Additionally, each unit estimated the overall number of working hours devoted to the project in a week. The time spent per person was calculated by dividing the weekly workload by the average number of patients invited per week.

PHCUs were also questioned about the implementation of public health programmes in the past. Public health programmes were defined as any forms of public health activities separately funded and monitored.

\section{Statistical analysis}

Since both individual-level and PHCU-level factors associated with non-response were analysed, multilevel modelling was applied. Individual covariates included age, gender and place of residence. PHCU-level covariates involved ownership, the number of patients registered, prior experience in public health programmes, presence of local promotion programme, mode of invitation, number of personnel involved and number of working hours per patient.

A multilevel logistic model was developed with fixed effects and only a random intercept for the unit. Preliminary analysis included a random effect for unit and each of the individual-level or PHCU-level covariates separately. Owing to a small number of PHCUs, construction of a single model accounting for all PHCU's variables was not feasible. For each PHCU-level covariates, we applied a two-level model with individual-level covariates, unit random effect and a single fixed effect of this unit-level covariate.

\section{Laboratory methods}

Serum samples were processed using EIA (Cobas e 411, Roche). Samples that were repeatedly reactive were subject to PCR (Qiagen). 
Anti-HCV and HCV RNA prevalence were calculated relating the number of anti-HCV and HCV RNA-positive individuals to the total population. We calculated crude prevalence and prevalence standardised to the year of birth and gender distribution in the population of Poland as of 2014.

Detailed analysis on the prevalence and related factors was beyond the scope of this article and will be reported separately.

\section{RESULTS}

\section{PHCUs}

Between November 2012 and April 2014, 242 PHCUs were invited (telephone, fax, letter, email). Each PHCU was given 2 weeks for consideration and then recontacted. Of the 242 PHCUs, 98 (40\%) refused, 91 (38\%) did not provide their final decision and 53 (22\%) agreed to participate in the study, but then 9 of them resigned. Finally, 44 PHCUs $(18 \%)$ were enrolled (figure 1).

Each of the 44 PHCUs was required to attend training on the project's procedure (table 1 ).

The majority of them were medium-sized units (25009999 patients registered; $56.8 \%$ ) and privately owned $(81.8 \%)$. Over $90 \%$ had prior experience in running public health programmes. Only a quarter of the units tried to implement passive recruitment strategies and only one relied on letter-based invitations. The burden of the project was assessed at 7 hours/week on average. Most of the PHCUs assigned up to two persons who coordinated the project (most often nurses).

\section{Patients}

Between March 2013 and March 2015, 24480 individuals aged between 18 and 94 years (median 48.5 years) were invited (figure 2).

Of note, $64 \%$ of them were women and the majority lived in rural areas $(46.7 \%)$ or small towns $(<20000$ inhabitants; $18.2 \%$; table 2).

\section{Factors related to non-response}

Of all individuals, 20939 (85.5\%) agreed to participate in the study. The non-response rate was relatively low, that is, $14.5 \%$.

Factors associated with non-response are presented in table 3 .

Adjusted for the population structure (age, gender, place of residence), PHCU-level factors and recruitment strategies were important predictors of non-response. Unit random effect was significant in all models. Larger and private units reported higher non-response rates. For those with a history of running public health programmes, the odds of non-response was lower (adjusted OR $(\mathrm{aOR})=0.8,95 \%$ CI 0.7 to 0.9$)$. Proactive recruitment $(\mathrm{aOR}=0.6,95 \%$ CI 0.5 to 0.6$)$, more working hours ( $\geq 10$ hours/ week) devoted to the project $(\mathrm{aOR}=0.7,95 \%$ CI 0.7 to 0.8$)$ and the patient ( $\geq 1$ vs
$<0.5$ hour/patient: aOR=0.1, $95 \%$ CI 0.02 to 0.8$)$ resulted in its higher acceptance. Higher number of personnel had no such effect. Moreover, having corrected for individual-level factors, the province where the unit was located was not a significant predictor of non-response.

Additionally, reasons of non-response were investigated. Predominant reasons of non-response were lack of interest $(1843 / 3541 ; 52 \%)$ and failure to contact the patient $(1455 / 3541 ; 41 \%)$. Other reasons were less notable, including lack of time $(99 / 3541 ; 2.8 \%)$, testing performed in the past $(95 / 3541 ; 2.7 \%)$, fear for testing or its result $(31 / 3541 ; 0.9 \%)$ and other reasons beyond patient's control $(22 / 3541 ; 0.6 \%)$ with the examples being comorbidities and age precluding patient from attending the visit.

\section{HCV prevalence}

A total of $228(1.10 \%)$ anti-HCV and $99(0.43 \%)$ HCV RNA-positive individuals were detected. Standardised prevalence of anti-HCV and HCV RNA were $1.14 \%$ (95\% CI $0.94 \%$ to $1.39 \%$ ) and $0.56 \%$ (95\% CI $0.41 \%$ to $0.74 \%)$, respectively.

\section{DISCUSSION}

This study reports on factors related to non-response rates in HCV screening programme in PHC in Poland. The non-response rate in the study was low (14.5\%) indicating its relatively high acceptability. Having acknowledged that individual and unit-related factors may be influential, we were able to identify more challenging settings and the positive impact of personnel engagement. These findings suggest possible ways to improve the execution of screening programmes in PHC.

High response rate in programmes implemented in primary care is compliant with the findings of the literature data. Many developed countries (the UK, Canada, the USA) underline the benefits resulting from screening conducted by general practitioners. ${ }^{26-28}$ Primary care offers relatively high level of care and provision of comprehensive range of services as illustrated by the countries which empowered PHC (eg, Denmark, Spain and the UK).$^{29}$ It is especially relevant for the delivery of public health services, including population screening. From a systematic review and meta-analysis of targeted $\mathrm{HCV}$ testing interventions results that direct strategies (eg, risk assessment and/or screening offered by personnel) were of higher effectiveness compared with the general strategies (eg, leaflets, posters, TV and radio spots). ${ }^{30-32}$ Additionally, such a low non-response rate may result from the fact that PHCUs were paid for each patient enrolled. Evaluation of ongoing cancer screening programmes showed much lower response rates ${ }^{11} 33$ which could be brought up to the levels similar to our study with more proactive approach. ${ }^{34}$ We speculate that the direct payment associated with patient recruitment 


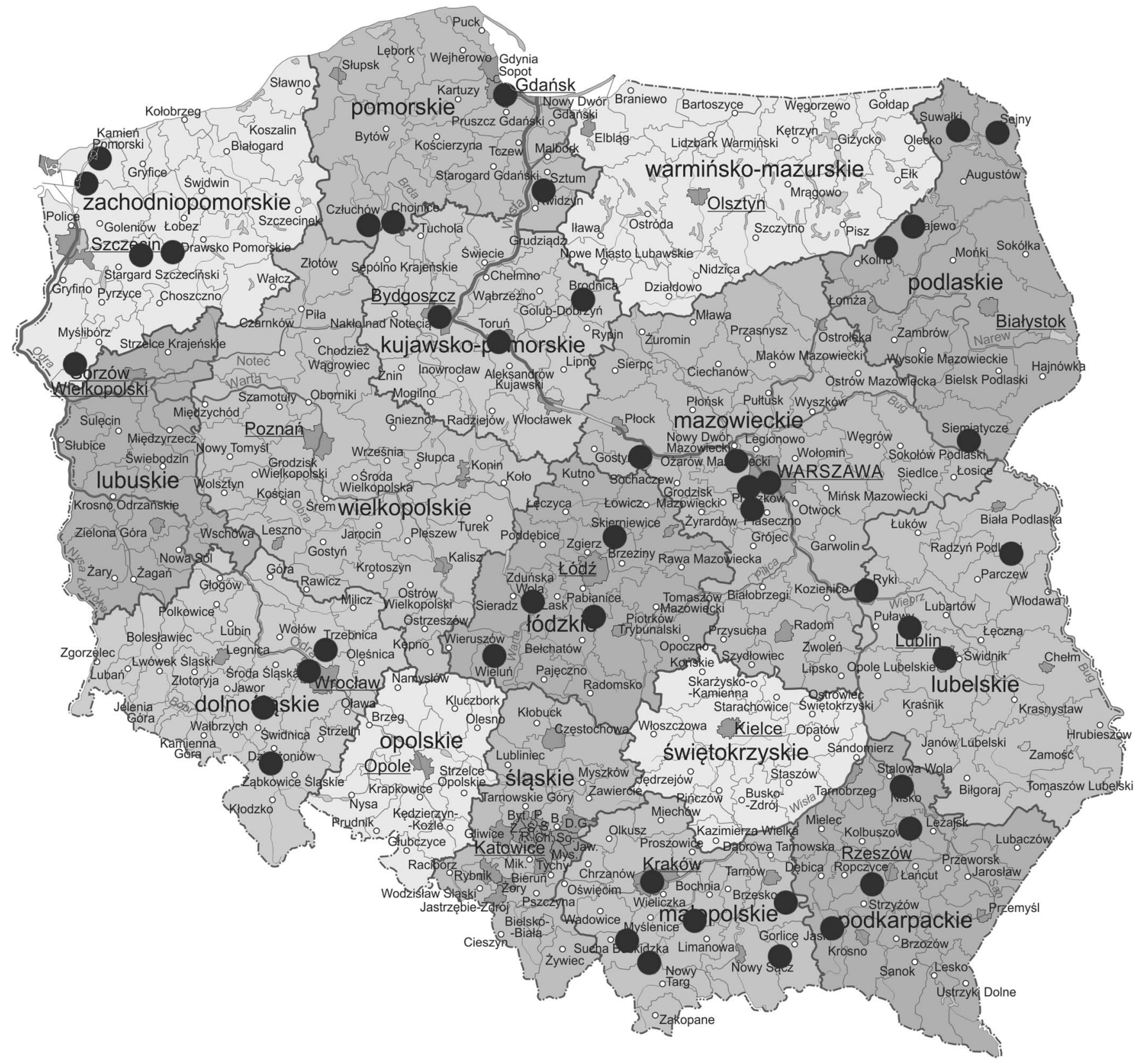

Figure 1 Locations of primary health care units enrolled in the study.

intensified the efforts to convince patients to participate in the programme. Furthermore, a short period predicted for the execution of the project could also have an effect on personnel motivation. We have to underline that the effort made by the personnel to recruit the patients from the list largely exceeded what can be expected on the routine bases. We showed the significant personnel time involvement. It was possible on a short time basis and with a financial incentive, but very likely would not be achievable in ongoing programmes. Moreover, we experienced a large non-response rate in PCHUs invited to take part in the project which could have resulted in self-selection of more motivated units. Its short duration could also prompt patients to take part in the study.
Prior experience in running public health programmes contributed to increased response rate. This underlines the role of gaining the experience, but also, potentially, increased health awareness of the population served.

Analysis of PHCU-level factors showed that private $(\mathrm{aOR}=1.2,95 \%$ CI 1.0 to 1.3$)$, and large units (25009999: $\mathrm{aOR}=3.6,95 \%$ CI 2.8 to 4.4 and $\geq 10000$ : $\mathrm{aOR}=2.3,95 \%$ CI 1.8 to 2.9 ) were more likely to note non-response. It may be indicative of better communication between healthcare providers and patients in public units rendering services for smaller populations. Possibly, healthcare workers may devote more time to provide the patient with information required to make an informed decision. Higher number of working hours 
Table 1 Characteristics of PHCUs and recruitment process

\begin{tabular}{|c|c|c|c|c|c|c|c|c|}
\hline & \multicolumn{2}{|c|}{$\begin{array}{l}\text { Primary care } \\
\text { units }\end{array}$} & \multicolumn{2}{|c|}{ Non-responders } & \multicolumn{2}{|c|}{ Responders } & \multicolumn{2}{|c|}{ Invited participants } \\
\hline & $\overline{\mathbf{N}}$ & Per cent & $\mathbf{N}$ & Per cent & $\mathbf{N}$ & Per cent & $\mathbf{N}$ & Per cent \\
\hline \multicolumn{9}{|l|}{ Unit size } \\
\hline$<2500$ & 7 & 15.9 & 139 & 3.9 & 2741 & 13.0 & 2880 & 11.7 \\
\hline 2500-9999 & 25 & 56.8 & 2766 & 78.1 & 12789 & 61.0 & 15555 & 63.5 \\
\hline $10000+$ & 12 & 27.2 & 636 & 17.9 & 5409 & 25.8 & 6045 & 24.6 \\
\hline \multicolumn{9}{|l|}{ Unit ownership } \\
\hline Public & 8 & 18.1 & 491 & 13.8 & 4341 & 20.7 & 4832 & 19.7 \\
\hline Private & 36 & 81.8 & 3050 & 86.1 & 16598 & 79.2 & 19648 & 80.2 \\
\hline \multicolumn{9}{|c|}{ Experience in running public health programmes in the past } \\
\hline No & 2 & 4.5 & 272 & 7.68 & 1449 & 6.9 & 1721 & 7.0 \\
\hline Yes & 42 & 95.4 & 3269 & 92.3 & 19490 & 93.0 & 22759 & 92.9 \\
\hline \multicolumn{9}{|l|}{ Local promotion } \\
\hline No & 34 & 77.2 & 2571 & 72.6 & 15774 & 75.3 & 18345 & 74.9 \\
\hline Yes & 10 & 22.7 & 970 & 27.3 & 5165 & 24.6 & 6135 & 25.0 \\
\hline \multicolumn{9}{|l|}{ Mode of invitation } \\
\hline Passive-active & 10 & 22.7 & 1342 & 37.9 & 4886 & 23.3 & 6228 & 25.4 \\
\hline Active-very active & 34 & 77.2 & 2199 & 62.1 & 16053 & 76.6 & 18252 & 74.5 \\
\hline \multicolumn{9}{|c|}{ Number of personnel involved in the project } \\
\hline $1-5$ & 22 & 50.0 & 1804 & 50.9 & 10728 & 51.2 & 12532 & 51.1 \\
\hline$>5$ & 22 & 50.0 & 1737 & 49.0 & 10211 & 48.7 & 11948 & 48.8 \\
\hline \multicolumn{9}{|c|}{ Working hours devoted to the programme (hours/week) } \\
\hline$<10$ & 34 & 77.2 & 2775 & 78.3 & 15235 & 72.7 & 18010 & 73.5 \\
\hline 10 or more & 10 & 22.7 & 766 & 21.6 & 5704 & 27.2 & 6470 & 26.4 \\
\hline \multicolumn{9}{|c|}{ Working hours per patient (hour) } \\
\hline$<0.5$ & 19 & 44.1 & 1922 & 54.5 & 9953 & 49.4 & 11875 & 50.1 \\
\hline 0.5 to $<1$ & 16 & 37.2 & 1324 & 37.5 & 7666 & 38.0 & 899 & 37.9 \\
\hline 1 or more & 8 & 18.6 & 278 & 7.8 & 2523 & 12.5 & 2801 & 11.8 \\
\hline Total & 44 & 100 & 3541 & 100 & 20939 & 100 & 24480 & 100 \\
\hline
\end{tabular}

PHCU, primary healthcare unit.

per patient $(0.5$ to $<1$ hour: aOR $=0.7,95 \%$ CI 0.2 to 2.8 and $\geq 1$ hour: aOR $=0.1,95 \%$ CI 0.02 to 0.8 ) resulted in higher response rates indicating that at least 0.5 hour (preferably $\geq 1$ hour) per patient should be allotted.

Channels of communication should also be considered. Information on the project was mainly disseminated via classic modes. Internet-based (websites, email) or mobilebased communication (SMS) was used by few PHCUs. As expected, we noted an increased risk of non-response in case of passive contact modes. Having considered lower non-response rates in PHCUs who adopted proactive recruitment, direct contact with patients should be emphasised. Literature data also provide evidence of higher effectiveness of proactive approach. ${ }^{35}$ We also noted that the implementation of local promotion of the programme was associated with lower response rates. As no precise data were available, we cannot exclude that this finding reflects the fact that programme promotion was implemented in response to unsatisfactory response rates.

Individual-level factors demonstrated that living in urban areas $(\geq 500000$ : aOR $=1.6,95 \%$ CI 1.4 to 1.8$)$, male gender $(\mathrm{aOR}=1.9,95 \%$ CI 1.8 to 2.1$)$ and age under 45 years (aOR=1.5, 95\% CI 1.4 to 1.6$)$ substantially predicted non-response in the study. Literature data also provide evidence for possible disparities in response with regard to gender, age, etc. ${ }^{36}$ At the same time surveillance data indicate that reaching young people, especially men, may be crucial to control HCV burden. European Centre for Disease Prevention and Control (ECDC) data as of 2014 suggest that hepatitis C is more frequent in males (male-to-female ratio: 1.8:1). Furthermore, individuals aged 25-44 years were the most affected group $(51.3 \%)$ and $8 \%$ of cases were aged $<25$ years. ${ }^{37}$ Available data show that the prevalence of $\mathrm{HCV}$ infection in the general population in Poland is about $0.6 \%$ (200 000 individuals). ${ }^{38} 39$ Moreover, routine surveillance data suggest that HCV incidence in young men, who were the most resistant to take part in our study, is higher. Furthermore, unlike in many European countries, HCV infections in Poland are not concentrated in specific risk groups (eg, people who inject drugs) ${ }^{40}$ This suggests a necessity of screening in the general population, potentially with more effort placed on the recruitment of younger men.

Having considered that the most common reason of refusal was the lack of interest, it may be speculated that men and younger individuals are less interested in their health, at least with regard to HCV infection. Low response rate in younger population may also result from logistic barriers, defined as non-flexibility of 


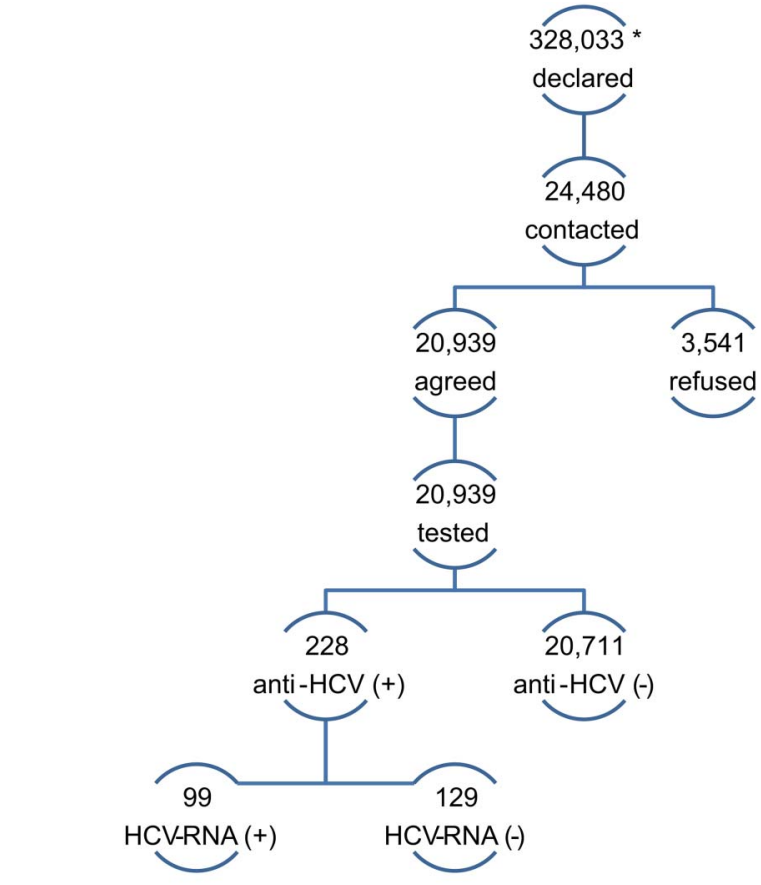

*total population of the PHCUs, including individuals aged $<18$ years old

Figure 2 Study population. HCV, hepatitis C virus; PHCU, primary healthcare unit.
PHCU's and patient's working schedule, which may hinder communication and arrangement of visit. In the era of modern communication technology, it may be also presumed that attempts to invite young individuals failed as they were not tailored to appropriate communication channels. ${ }^{41}$ Thus, it would be advisable to verify the effectiveness of novel technologies (eg, social media). ${ }^{42}$ It may be concluded that prior to the implementation of project, PHCUs should investigate opinions of potential responders on communication preferences to ensure its effectiveness. ${ }^{43}$

A limitation of our study may be associated with the fact that efficient PHCUs could have been overrepresented in our study. Such hypothesis may be strengthened by the long period of recruitment of PHCUs and high non-response rate observed. PHCUs who agreed to participate in the study had to differ from non-participating PHCUs in terms of involvement in public health initiatives and efficacy of their execution. Another limitation may result from the fact that the method of patient sampling employed by PHCUs was not universal. It could have an effect on high response rates; however, it was not feasible to impose one standard method of sampling on PHCUs. Moreover, PHCUs were instructed that they could not rely on the recruitment of volunteers. Furthermore, $41 \%$ of all non-

\begin{tabular}{|c|c|c|c|c|c|c|}
\hline & \multicolumn{2}{|c|}{ Non-responders } & \multicolumn{2}{|c|}{ Responders } & \multicolumn{2}{|l|}{ Invited } \\
\hline & $\mathbf{N}$ & Per cent & $\mathbf{N}$ & Per cent & $\mathbf{N}$ & Per cent \\
\hline Age (median/IQR, mean, SD) & \multicolumn{2}{|c|}{$\begin{array}{l}43.0 /(30.4-57.2), \\
45.1,0.28\end{array}$} & \multicolumn{2}{|c|}{$\begin{array}{l}48.5 /(35.1-59.4) \\
48.3,0.1\end{array}$} & \multicolumn{2}{|c|}{$\begin{array}{l}48.5 /(35.1-59.4) \\
47.9,0.1\end{array}$} \\
\hline \multicolumn{7}{|l|}{ Gender } \\
\hline Male & 1718 & 48.5 & 7093 & 33.87 & 8811 & 35.9 \\
\hline Female & 1823 & 51.4 & 13846 & 66.13 & 15669 & 64.0 \\
\hline \multicolumn{7}{|l|}{ Age group } \\
\hline$<45$ & 1887 & 53.2 & 8761 & 41.8 & 10648 & 43.5 \\
\hline $45+$ & 1654 & 46.7 & 12178 & 58.1 & 13832 & 56.5 \\
\hline \multicolumn{7}{|l|}{ Place of residence } \\
\hline Rural & 1541 & 43.5 & 9900 & 47.2 & 11441 & 46.7 \\
\hline City $<20000$ & 414 & 11.6 & 4038 & 19.2 & 4452 & 18.1 \\
\hline City $20000-49000$ & 434 & 12.2 & 2221 & 10.6 & 2655 & 10.8 \\
\hline City 50 000-99 000 & 196 & 5.5 & 811 & 3.8 & 1007 & 4.1 \\
\hline City $100000-499000$ & 207 & 5.8 & 2693 & 12.8 & 2900 & 11.8 \\
\hline City 500000 or larger & 749 & 21.1 & 1276 & 6.0 & 2025 & 8.2 \\
\hline \multicolumn{7}{|l|}{ Province } \\
\hline Dolnośląskie & 236 & 6.6 & 1946 & 9.2 & 2182 & 8.9 \\
\hline Kujawsko-pomorskie & 158 & 4.4 & 1845 & 8.8 & 2003 & 8.1 \\
\hline Lubelskie & 223 & 6.3 & 2469 & 11.7 & 2692 & 11.0 \\
\hline Łódzkie & 682 & 19.2 & 2117 & 10.1 & 2799 & 11.4 \\
\hline Małopolskie & 888 & 25.0 & 3143 & 15.0 & 4031 & 16.4 \\
\hline Mazowieckie & 277 & 7.8 & 1980 & 9.4 & 2257 & 9.2 \\
\hline Podkarpackie & 431 & 12.1 & 1820 & 8.6 & 2251 & 9.2 \\
\hline Podlaskie & 256 & 7.2 & 2064 & 9.8 & 2320 & 9.4 \\
\hline Pomorskie & 216 & 6.1 & 1674 & 7.9 & 1890 & 7.7 \\
\hline Zachodniopomorskie & 174 & 4.9 & 1881 & 8.9 & 2055 & 8.3 \\
\hline Total & 3541 & 100 & 20939 & 100 & 24480 & 100 \\
\hline
\end{tabular}


Table 3 Factors associated with increased odds of non-response

\begin{tabular}{|c|c|c|c|c|c|c|}
\hline & \multicolumn{2}{|l|}{ Univariable analysis } & \multicolumn{2}{|c|}{$\begin{array}{l}\text { Individual-level factors and RE } \\
\text { of unit model* }\end{array}$} & \multicolumn{2}{|c|}{$\begin{array}{l}\text { Models adjusted for the } \\
\text { individual-level effects } \\
\text { and RE of unit } †\end{array}$} \\
\hline & OR (95\% Cl) & p Value & aOR (95\% Cl) & p Value & aOR (95\% Cl) & p Value \\
\hline Individual-level effects & Non-responders $(n=3541)$ & & Responders ( $n=20$ 939) & & & \\
\hline \multicolumn{7}{|l|}{ Gender } \\
\hline Female & Ref & $<0.001$ & Ref & $<0.001$ & - & \\
\hline Male & 1.8 (1.7 to 2$)$ & & 1.9 (1.8 to 2.1$)$ & & & \\
\hline \multicolumn{7}{|l|}{ Age } \\
\hline$\geq 45$ & Ref & $<0.001$ & Ref & $<0.001$ & - & \\
\hline$<45$ & $1.6(1.5$ to 1.7$)$ & & 1.5 (1.4 to 1.6$)$ & & & \\
\hline \multicolumn{7}{|l|}{ Place of residence } \\
\hline$<500000$ & Ref & $<0.001$ & Ref & $<0.001$ & - & \\
\hline$\geq 500000$ & 4.1 (3.7 to 4.6$)$ & & $1.6(1.4$ to 1.8$)$ & & & \\
\hline PHCU-level effects & PHCUs $(n=44)$ & & & & & \\
\hline \multicolumn{7}{|l|}{ Unit size } \\
\hline$<2500$ & Ref & $<0.001$ & - & & Ref & $<0.001$ \\
\hline 2500-9999 & 4.3 (3.6 to 5.1$)$ & & & & 3.6 (2.8 to 4.4$)$ & \\
\hline$\geq 10000$ & 2.3 (1.9 to 2.8$)$ & & & & 2.3 (1.8 to 2.9$)$ & \\
\hline \multicolumn{7}{|l|}{ Unit ownership } \\
\hline Public & Ref & $<0.001$ & - & & Ref & 0.009 \\
\hline Private & $1.6(1.5$ to 1.8$)$ & & & & $1.2(1$ to 1.3$)$ & \\
\hline \multicolumn{7}{|c|}{ Experience in running public health programmes in the past } \\
\hline No & Ref & 0.101 & - & & Ref & 0.005 \\
\hline Yes & $0.9(0.8$ to 1$)$ & & - & & $0.8(0.7$ to 0.9$)$ & \\
\hline \multicolumn{7}{|c|}{ Local promotion programme } \\
\hline No & Ref & 0.001 & & & Ref & $<0.001$ \\
\hline Yes & $1.2(1.1$ to 1.2$)$ & & - & & $1.4(1.3$ to 1.6$)$ & \\
\hline \multicolumn{7}{|l|}{ Mode of invitation } \\
\hline Passive-active & Ref & $<0.001$ & - & & Ref & $<0.001$ \\
\hline Active-very active & $0.5(0.5$ to 0.5$)$ & & & & $0.6(0.5$ to 0.6$)$ & \\
\hline \multicolumn{7}{|c|}{ Number of personnel involved in the project } \\
\hline $1-5$ & Ref & 0.751 & - & & Ref & $<0.001$ \\
\hline$>5$ & $1(0.9$ to 1.1$)$ & & & & $1.4(1.2$ to 1.6$)$ & \\
\hline \multicolumn{7}{|c|}{ Working hours devoted to the project (hours/week) } \\
\hline$<10$ & Ref & $<0.001$ & - & & Ref & $<0.001$ \\
\hline$\geq 10$ & $0.7(0.7$ to 0.8$)$ & & & & $0.7(0.7$ to 0.8$)$ & \\
\hline \multicolumn{7}{|c|}{ Working hours per patient (hour) } \\
\hline$<0.5$ & Ref & $<0.001$ & & & Ref & 0.0921 \\
\hline $0.5-<1$ & 0.9 (0.8 to 0.97$)$ & & & & $0.7(0.2$ to 2.8$)$ & \\
\hline$\geq 1$ & $0.6(0.5$ to 0.7$)$ & & & & 0.1 (0.02 to 0.8$)$ & \\
\hline
\end{tabular}

responders could not be contacted. Since only a small proportion of them were due to working or studying in another city or abroad, we included this group in the analysis as it may substantially limit the coverage of public health interventions. Additionally, due to the small number of PHCUs, we were unable to study the independent effects of all unit-level factors. Moreover, we could not investigate other predictors which could be useful to identify specific groups who respond poorly to screening programmes. However, we were only allowed to collect basic information on non-responders available through the registration database.
In conclusion, our results suggest that individual and PHCU-related factors may considerably affect response rates in public health programmes. Actually, some of them may constitute strong predictors of non-response. Thus, it is important to identify such factors and address them in an appropriate manner. Irrespective of the difficulties encountered by PHCUs, it seems to be a very effective setting for the detection of HCV infections. It may result from better physician-patient communication and recognition of local population which ensures intervention targeting. On the other hand, there is evidence of experience and knowledge deficits in the 
management of HCV cases among general practitioners. ${ }^{44}$ Therefore, special efforts should be undertaken to expand their competences. Evaluation of factors associated with increased odds of non-response in the project revealed several elements that could be resolved in future public health programmes.

\section{CONCLUSIONS}

Based on the results of the ongoing project, we can present the following conclusions:

1. Individuals living in urban areas, especially young men, constitute a group for which it is required to develop better communication strategies. They were represented to the largest extent in the group of non-responders.

2. Prior to the implementation of public health programme, if possible, PHCU's capacity to manage new tasks should be investigated.

3. Having considered the heterogeneity of patients (age, gender, place of residence) targeted for public health interventions, an emphasis should be put on recruitment strategies, tailoring and marketing messages.

\section{Author affiliations}

${ }^{1}$ Department of Epidemiology, National Institute of Public Health-National Institute of Hygiene, Warsaw, Poland

${ }^{2}$ Department of Virology, National Institute of Public Health-National Institute of Hygiene, Warsaw, Poland

${ }^{3}$ Department of Epidemiology, Medical University of Warsaw, Warsaw, Poland

Acknowledgements The authors would like to acknowledge the colleagues from Primary Health Care Units who participated in the study.

Contributors NP collected the data, prepared the database for the analysis, elaborated the draft version of the manuscript and coordinated the works on manuscript. MS provided input and comments to manuscript. KZ participated in laboratory data processing, provided input and comments to manuscript. $\mathrm{KM}$ participated in laboratory data processing, provided comments to manuscript. AK and PG carried out laboratory testing, provided comments to manuscript. MR coordinated the study, participated in the design of the study, conducted the statistical analysis, provided input and comments to manuscript. All authors read, revised and approved the final version of manuscript.

Funding This work was supported by grant number KIK 35 'Prevention of HCV Infections' from Switzerland through the Swiss Contribution to the enlarged European Union and the Minister of Health of the Republic of Poland.

\section{Competing interests None declared.}

Ethics approval The Ethics Committee of the National Institute of Public Health-National Institute of Hygiene in Warsaw (no. 6/2012 as of 4th October 2012) approved the study.

Provenance and peer review Not commissioned; externally peer reviewed.

Data sharing statement No additional data are available.

Open Access This is an Open Access article distributed in accordance with the Creative Commons Attribution Non Commercial (CC BY-NC 4.0) license, which permits others to distribute, remix, adapt, build upon this work noncommercially, and license their derivative works on different terms, provided the original work is properly cited and the use is non-commercial. See: http:// creativecommons.org/licenses/by-nc/4.0/

\section{REFERENCES}

1. Cramp ME, Rosenberg WM, Ryder SD, et al. Modelling the impact of improving screening and treatment of chronic hepatitis $C$ virus infection on future hepatocellular carcinoma rates and liver-related mortality. BMC Gastroenterol 2014;14:137.

2. Goessens BM, Visseren FL, Algra A, et al. Screening for asymptomatic cardiovascular disease with noninvasive imaging in patients at high-risk and low-risk according to the European Guidelines on Cardiovascular Disease Prevention: the SMART study. J Vasc Surg 2006;43:525-32.

3. Buckley BS, Harreiter J, Damm P, et al. Gestational diabetes mellitus in Europe: prevalence, current screening practice and barriers to screening. A review. Diabet Med 2012;29:844-54.

4. Esserman LJ, Thompson IM, Reid B, et al. Addressing overdiagnosis and overtreatment in cancer: a prescription for change. Lancet Oncol 2014;15:e234-42.

5. de Vos AS, Kretzschmar ME. Benefits of hepatitis C virus treatment: a balance of preventing onward transmission and re-infection. Math Biosci 2014;258:11-18.

6. Hamlyn $\mathrm{E}$, Jones $\mathrm{V}$, Porter $\mathrm{K}$, et al. Antiretroviral treatment of primary HIV infection to reduce onward transmission. Curr Opin HIV AIDS 2010;5:283-90.

7. Mercer $\mathrm{CH}$, Aicken $\mathrm{CR}$, Brook MG, et al. Estimating the likely public health impact of partner notification for a clinical service: an evidence-based algorithm. Am J Public Health 2011;101: 2117-23.

8. European Centre for Disease Prevention and Control. Prevention and control of infectious diseases among people who inject drugs. http://ecdc.europa.eu/en/publications/_layouts/forms/Publication DispForm.aspx?ID=487\&List=4f55ad51-4aed-4d32-b960af70113dbb90 (accessed 25 Nov 2014).

9. European Centre for Disease Prevention and Control. Novel approaches to testing for sexually transmitted infections, including HIV and hepatitis B and C in Europe. http://ecdc.europa.eu/en/ publications/_layouts/forms/Publication_DispForm.aspx? List=4f55ad51-4aed-4d32-b960-af70113dbb90\&ID=712 (accessed 25 Nov 2014)

10. European Cancer Observatory-IARC. Estimated incidence and mortality from cervical cancer in women. 2012. http://eco.iarc.fr/ EUCAN/CancerOne.aspx?Cancer=25\&Gender=2 (accessed 11 Aug 2015).

11. Nowakowski A, Cybulski M, Śliwczyński A, et al. The implementation of an organised cervical screening programme in Poland: an analysis of the adherence to European guidelines. BMC Cancer 2015;15:279.

12. Januszek-Michalecka L, Nowak-Markwitz E, Banach P, et al. Effectiveness of the National Population-Based Cervical Cancer Screening Programme in Poland-outcomes, problems and possible solutions 7 years after implementation. Ann Agric Environ Med 2013;20:859-64.

13. Grunfeld E, Manca D, Moineddin R, et al. Improving chronic disease prevention and screening in primary care: results of the BETTER pragmatic cluster randomized controlled trial. BMC Fam Pract 2013;14:175.

14. Manca DP, Aubrey-Bassler K, Kandola K, et al. Implementing and evaluating a program to facilitate chronic disease prevention and screening in primary care: a mixed methods program evaluation. Implement Sci 2014;9:135.

15. Campbell C, Anandan C, Appleton S, et al. Avoiding inappropriate invitations to cancer screening programmes: the role of primary care. J Med Screen 2011;18:12-17.

16. Ranasinghe WK, Kim SP, Papa NP, et al. Prostate cancer screening in primary health care: the current state of affairs. Springerplus $2015 ; 4: 78$

17. Klabunde CN, Marcus PM, Han PK, et al. Lung cancer screening practices of primary care physicians: results from a national survey. Ann Fam Med 2012;10:102-10.

18. Austoker J. Cancer prevention in primary care: screening for cervical cancer. BMJ 1994;309:241-8.

19. World Health Organization. The World Health Report 2008-primary Health Care (Now More Than Ever). http://www.who.int/whr/2008/en/ (accessed 19 Jun 2015).

20. Kringos DS, Boerma WG, Hutchinson A, et al. The breadth of primary care: a systematic literature review of its core dimensions. BMC Health Serv Res 2010;10:65.

21. Starfield B. Primary care: an increasingly important contributor to effectiveness, equity, and efficiency of health services. SESPAS report 2012. Gac Sanit 2012;26(Suppl 1):20-6.

22. Girouard N, Imai Y. The health care system in Poland. Economics department working papers no.257. Paris: OECD, 2000. http://www. oecd.org/Poland/ (accessed 19 Jun 2015). 
23. Rechel B, McKee M. Health reform in central and Eastern Europe and the former Soviet Union. Lancet 2009;374:1186-95.

24. Ministry of Health of the Republic of Poland. http://www.mz.gov.pl/ leczenie/poz (accessed 13 Jul 2015).

25. Central Statistical Office. Health and health care in 2010. http://stat. gov.pl/en/topics/health/health/health-and-health-care-in2010,1,4.htm (accessed 19 Jun 2015).

26. Cox J, Graves L, Marks E, et al. Knowledge, attitudes and behaviours associated with the provision of hepatitis $C$ care by Canadian family physicians. J Viral Hepat 2011;18:e332-40.

27. Mitruka K, Thornton K, Cusick S, et al. Expanding primary care capacity to treat hepatitis $C$ virus infection through an evidence-based care model-Arizona and Utah, 2012-2014. MMWR Morb Mortal Wkly Rep 2014;63:393-8.

28. Royal College of General Practitioners. Detecting and managing hepatitis C in primary care. http://www.rcgp.org.uk/news/2015/april/ new-film-putshep-c-in-the-primary-care-spotlight.aspx (accessed 13 Jul 2015).

29. Kringos DS, Boerma WG, Hutchinson A, et al. Building primary care in a changing Europe. http://www.euro.who.int/en/publications/abstracts/ building-primary-care-in-a-changing-europe (accessed 11 Aug 2015).

30. Jones L, Bates G, McCoy E, et al. Effectiveness of interventions to increase hepatitis $\mathrm{C}$ testing uptake among high-risk groups: a systematic review. Eur J Public Health 2013;24:781-8.

31. Litwin AH, Smith BD, Drainoni ML, et al. Primary care-based interventions are associated with increases in hepatitis $C$ virus testing for patients at risk. Dig Liver Dis 2012;44:497-503.

32. Helsper CW, van Essen GA, Bonten MJ, et al. A support programme for primary care leads to substantial improvements in the effectiveness of a public hepatitis C campaign. Fam Pract 2010;27:328-32.

33. Leźnicka M, Mierzwa T, Jachimowicz-Wołoszynek D, et al. The individual invitation system vs. women's attendance rate at preventive tests performed as a part of oncological prevention programs. Probl Hig Epidemiol 2009;90:627-30.

34. Galor A, Cybulski C, Lubiński J, et al. Optimizing recruitment to a prostate cancer surveillance program among male BRCA1 mutation carriers: invitation by mail or by telephone. Hered Cancer Clin Pract 2013;11:17.

35. World Health Organization. Guidelines for the screening, care and treatment of persons with hepatitis $C$ infection. http://www. who.int/hiv/pub/hepatitis/hepatitis-c-guidelines/en/ (accessed 25 Nov 2014).

36. Koopmans B, Nielen MM, Schellevis FG, et al. Non-participation in population-based disease prevention programs in general practice. BMC Public Health 2012;12:856.

37. European Centre for Disease Prevention and Control. Hepatitis C surveillance in Europe. http://ecdc.europa.eu/en/healthtopics/ hepatitis_c/Pages/Annual-Epidemiological-Report.aspx (accessed 1 Sep 2016).

38. Flisiak R, Halota W, Horban A, et al. Prevalence and risk factors of $\mathrm{HCV}$ infection in Poland. Eur J Gastroenterol Hepatol 2011;23:1213-17.

39. Sakem B, Madaliński K, Nydegger U, et al. Hepatitis C virus epidemiology and prevention in Polish and Swiss populationsimilar and contrasting experiences. Ann Agric Environ Med 2016;23:425-31.

40. Parda N, Rosińska M, Stepień M. Hepatitis C in Poland in 2013. Przegl Epidemiol 2015;69:375-8.

41. Hesse BW, Nelson DE, Kreps GL, et al. Trust and sources of health information. The impact of the internet and its implications for health care providers: findings from the first health information national trends survey. Arch Intern Med 2005;165:2618-24.

42. Odone A, Ferrari A, Spagnoli F, et al. Effectiveness of interventions that apply new media to improve vaccine uptake and vaccine coverage: a systematic review. Hum Vaccin Immunother 2014;11:72-82.

43. Wingfield $\mathrm{JH}$, Reese $\mathrm{L}$. Trust for health information: differences by race, age, education and gender. 2009. http://hints.cancer.gov/docs/ 2009/wingfield-trust.pdf (accessed 25 Nov 2014).

44. McGowan CE, Monis A, Bacon BR, et al. A global view of hepatitis $\mathrm{C}$ : physician knowledge, opinions, and perceived barriers to care. Hepatology 2013;57:1325-32. 